\title{
Mediastinal ectopic thyroid video-assisted thoracic surgery (VATS) excision: a case report
}

\author{
Michele Ferrari $^{1,2}$, Valeria Musso ${ }^{1,2}$, Cristina Diotti $^{1,2}$, Davide $^{\text {Tosi }}{ }^{1,2}$ \\ ${ }^{1}$ Department of Pathophysiology and Transplantation, University of Milan, Milan, Italy; ${ }^{2}$ Thoracic Surgery and Lung Transplantation Unit, \\ Fondazione IRCCS Ca' Granda - Ospedale Maggiore Policlinico, Milan, Italy \\ Correspondence to: Michele Ferrari, MD. Division of Thoracic Surgery and Lung transplant Unit, Fondazione IRCCS Ca' Granda - Ospedale \\ Maggiore Policlinico Via Francesco Sforza, 3520123 Milan, Italy. Email: michele.ferrari1990@gmail.com.
}

\begin{abstract}
Ectopic thyroid tissue is caused by an anomaly in the development or migration of thyroid tissue. The lingual thyroid tissue (at the base or below the tongue), accounts for $90 \%$ of these abnormalities. Except for the neck, the most common localization for ectopic thyroid cells is the mediastinum; ectopic thyroid tissue therefore needs to be considered in the differential diagnosis of all mediastinal masses. The mediastinal ectopic thyroid gland is a rare entity, representing about $1 \%$ of all mediastinal tumors for example lymphomas, thymic tumors, dermoid cysts and mediastinal ectopic thyroid which need different management and treatment. Patients with mediastinal ectopic thyroid tissue are often asymptomatic; the most common symptoms are dysphagia, dyspnea, voice hoarseness, which are usually caused by the compression of mediastinal structures. We describe a case of a mediastinal ectopic thyroid, which was surgically excised via triportal video-assisted thoracic surgery (VATS). The patient was a 50-year-old female with a history of renal cell carcinoma. Her chest computed tomography (CT) scan during radiological surveillance revealed a lesion in the left anterior mediastinum; the patient was asymptomatic. The frozen section examination found the presence of thyroid parenchymal cells, which was later confirmed by the histological exam. Postoperative course was uneventful, and the patient was discharged on the third postoperative day.
\end{abstract}

Keywords: Ectopic thyroid; video-assisted thoracic surgery (VATS); case report

Received: 22 November 2020; Accepted: 07 January 2021.

doi: $10.21037 /$ jovs-20-167

View this article at: http://dx.doi.org/10.21037/jovs-20-167

\section{Introduction}

Ectopic thyroid tissue is caused by an anomaly in either development or migration of thyroid tissue. Commonly, this abnormality can be found along the obliterated thyroglossal duct, but other less frequent sites, such as the mediastinum, have been reported (1). Mediastinal ectopic thyroid tissue accounts for about $1 \%$ of mediastinal tumours (2), yet it needs to be considered in the differential diagnosis and management of all mediastinal masses. Here, we present a case of mediastinal ectopic thyroid minimally invasive excision, in accordance with the CARE reporting checklist (available at http://dx.doi.org/10.21037/jovs-20-167).

\section{Case presentation}

A 50-year-old female with a history of renal cell carcinoma was referred to our unit after a mediastinal mass was found on her chest computed tomography (CT) scan during radiological surveillance. The $\mathrm{CT}$ scan showed the presence of a $20 \mathrm{~mm} \times 16 \mathrm{~mm} \times 12 \mathrm{~mm}$ oval shaped lesion with contrast-enhancement in the left anterior mediastinum. The lesion was located alongside the aortic arch, without any sign of compression (Figure 1). The patient was asymptomatic; she reported no previous illnesses except for a right nephrectomy the year before for a kidney carcinoma (pT1bN0). The neck and chest examination was normal. 


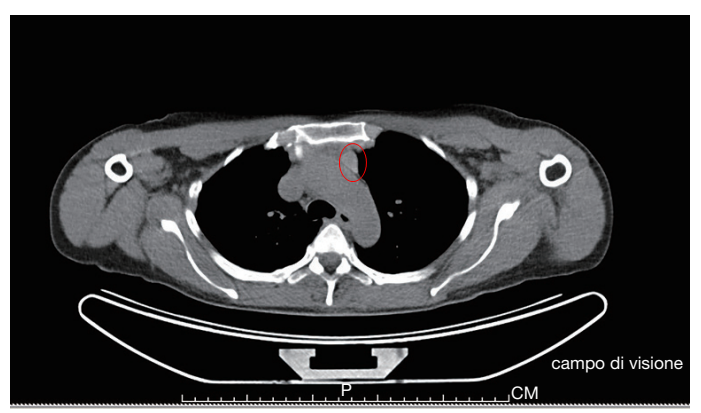

Figure 1 CT images of anterior mediastinal mass (the oval).

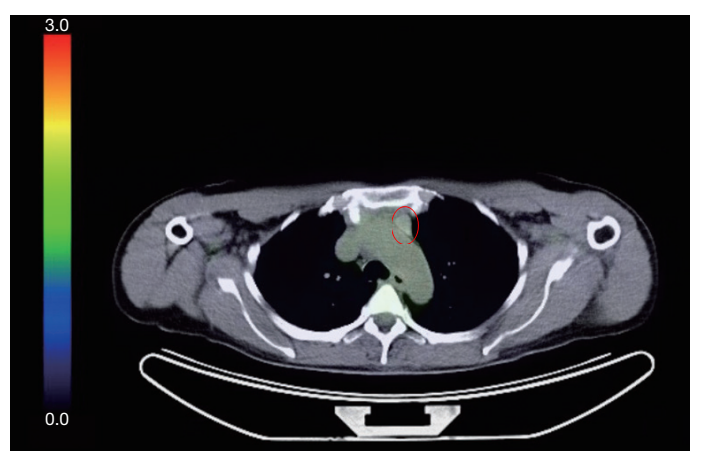

Figure 2 18F-fluorodeoxyglucose positron emission tomography/ computed tomography $\left({ }^{18} \mathrm{~F}\right.$-FDG PET/CT) of anterior mediastinal mass (the oval).

The diagnostic assessment included a PET scan (Figure 2), which was negative, and preoperative blood tests, which were normal. The results of thyroid function tests such as T4, TSH, anti-TPO and anti-TG was normal.

We decided to proceed with surgical excision, which was performed via triportal VATS. Anterior pleural adhesions were dissected. At visual inspection the mediastinal lesion appeared yellowish, and had a rubbery, soft consistency. Frozen section was negative for malignancy, but found the presence of thyroid parenchymal cells (Video 1). Postoperative course was uneventful, and calcium levels remained normal after surgery; the patient was discharged on the third postoperative day without thyroid replacement therapy. The definitive histological exam confirmed the diagnosis of ectopic thyroid tissue with no signs of malignancy. The patient was referred to the endocrinologist for follow-up.

All procedures performed were in accordance with the ethical standards of the institutional research committee and with the Helsinki Declaration (as revised in 2013). Written informed consent was obtained from the patient.

\section{Discussion}

Ectopic thyroid tissue can be the result of an abnormal growth of thyroid cells or their migration. This condition is more common in females, and usually occurs in adolescents or near climacterium. The patient is often asymptomatic and the lesion is discovered incidentally, unless mediastinal structures are involved. The most common symptoms are dysphagia, dyspnea, voice hoarseness, which are usually caused by compression of different structures in the mediastinum (esophagus, airways, recurrent laryngeal nerve); in this case surgery becomes mandatory. In fact, in many cases the mass tends to grow, with the risk of causing the compression of other structures, making surgical excision more invasive. Also, in up to $25 \%$ of cases, malignant cells are found in the histological exams (3). In our case, however, the patient was asymptomatic. Different surgical approaches can be adopted depending on the lesion's characteristic. Regal et al. describe the excision of a large mediastinal ectopic thyroid via midline partial sternotomy (1); in 2018, Metere et al. reported a case of mediastinal ectopic thyroid, which was surgically removed through a double approach consisting of a cervicotomy for the left thyroid lobectomy, and an upper partial sternal split extended to a fourth intercostal space thoracotomy for the mediastinal lesion (4). Gamblin et al. first employed a cervical incision to explore the thyroid and perform a left thyroid lobectomy, but the excision of the intrathoracic goiter required a median sternotomy (2). In our case, surgical excision via VATS allowed us to obtain a diagnosis using a minimally invasive approach with no complication or morbidity for our patient.

\section{Acknowledgments}

Funding: None.

\section{Footnote}

Reporting Checklist: The authors have completed the CARE reporting checklist. Available at http://dx.doi.org/10.21037/ jovs-20-167

Conflicts of Interest: All authors have completed the ICMJE uniform disclosure form (available at http://dx.doi. org/10.21037/jovs-20-167). The authors have no conflicts of interest to declare.

Ethical Statement: The authors are accountable for all 
aspects of the work in ensuring that questions related to the accuracy or integrity of any part of the work are appropriately investigated and resolved. All procedures performed were in accordance with the ethical standards of the institutional research committee and with the Helsinki Declaration (as revised in 2013). Written informed consent was obtained from the patient.

Open Access Statement: This is an Open Access article distributed in accordance with the Creative Commons Attribution-NonCommercial-NoDerivs 4.0 International License (CC BY-NC-ND 4.0), which permits the noncommercial replication and distribution of the article with the strict proviso that no changes or edits are made and the original work is properly cited (including links to both the formal publication through the relevant DOI and the license).

doi: 10.21037 /jovs-20-167

Cite this article as: Ferrari M, Musso V, Diotti C, Tosi D. Mediastinal ectopic thyroid video-assisted thoracic surgery (VATS) excision: a case report. J Vis Surg 2021.
See: https://creativecommons.org/licenses/by-nc-nd/4.0/.

\section{References}

1. Regal M, Kamel MM, Alyami H, et al. Mediastinal ectopic thyroid mass with normal thyroid function and location: Case report. Int J Surg Case Rep 2018;52:5-7.

2. Gamblin TC, Jennings GR, Christie DB 3rd, et al. Ectopic thyroid. Ann Thorac Surg 2003;75:1952-3.

3. Simó R, Nixon IJ, Vander Poorten V, et al. Surgical management of intrathoracic goitres. Eur Arch Otorhinolaryngol 2019;276:305-14.

4. Metere A, De Giacomo T, Vergine M, et al. Diagnosis and management of a mediastinal ectopic thyroid laying on the right bronchus: case report and review of literature. BMC Surg 2018;18:19. 